\title{
Neuropsychological Profile of Adopted Children - A Clinic Based Study
}

\author{
Virudhagirinathan Baboo Sankar, , , Amira Parveen Shakir ${ }^{1}$, Govindaraju Soundararajan ${ }^{2}$ \\ ${ }^{1}$ Care Institute of Behavioural Sciences, Chennai, Tamil Nadu, India \\ ${ }^{2}$ Chettinad Academy of Research \& Foundation, Chennai, Tamil Nadu, India
}

Email address:

drbsv18@gmail.com (Virudhagirinathan B. S.), aamira0404@gmail.com (Amira P. S.), sg_raju49@yahoo.co.in (Govindaraju S.)

*Corresponding author

\section{To cite this article:}

Virudhagirinathan Baboo Sankar, Amira Parveen Shakir, Govindaraju Soundararajan. Neuropsychological Profile of Adopted Children - A Clinic Based Study. American Journal of Psychiatry and Neuroscience. Vol. 5, No. 6, 2017, pp. 78-82. doi: 10.11648/j.ajpn.20170506.14

Received: October 12, 2017; Accepted: November 13, 2017; Published: December 14, 2017

\begin{abstract}
The study aims to see the level of neuropsychological functions Intelligence, Memory, Attention \& Concentration and other mental abilities and Specific Learning Disability (SLD) in adopted children. A clinic based sample of 22 adopted children, Male 13, Female 9. Besides demographic variables, intelligence, memory, other mental abilities and SLD were assessed by Standardized Psychological Tests and HELP CHILD Learning Disability Assessment Tool. Neuropsychological profile showed more percentage of adopted children have average IQ and above average PQ. One fifth of children have impairment in memory, attention and concentration. Almost all the adopted children have Specific Learning Disability.
\end{abstract}

Keywords: Adoption, Memory, Intelligence, Specific Learning Disability

\section{Introduction}

Adoption is a substitute form of child rearing practice, wherein the parent child status is conferred upon one or more adults and a child. It meets a child's biological needs, gives physical security and provides emotional as well as social support. Adoption is a means of fulfilling the emotional needs of a childless couple [1]. Child adoption is a ubiquitous and time-honored practice [2].

After World War II, adoption became more common and more widely accepted than it had been before. For the first time, a broad white middle-class consensus proclaimed adoption the 'best solution' to the 'problem' of pregnancy out of wedlock.

The face of adoption changed significantly over time. The term Closed adoption was introduced where neither the child nor the biological parents knew the identity of the adoptive parents. Starting in the 1980 s, adoption agencies began to utilize the concept of open adoption. The concept was that birth mothers who were ambivalent about giving up their children into anonymity forever might be willing to grant adoption if they knew more about where and with whom their children were placed [3]. The provision of adoptive or foster placement is seen as providing optimum care solution for those children whose parents are unable or unwilling to care for them. Hence, adoption is more likely than not to transform as deprived or disadvantaged child's life [4].

Most of the research done with regard to adoption and the dilemma of adoptive parents and adopted children has been in the Western countries. Currently, adoption is gaining new grounds in India and is open to single unmarried women. Most of the studies are related to behavioral problems, adjustment and relationship of the adopted children with their adoptive parents [5].

Various studies revealed that the number of adopted children registered in clinics ranges from 2.9 to $21.2 \%$ [6], [7].

Adopted children show more psychological / behavioral problems than non adopted children [8], [9].

Hence, we made an attempt to study the level of neuropsychological functions - Intelligence, Memory, Attention \& Concentration and other mental abilities and Specific Learning Disability (SLD) in adopted children.

\section{Methodology}

The sample of the study is 22 adopted children consisting 
of 13 Male, 9 Female who were referred by Pediatricians, Neurologists, Psychiatrists, School counselors and school authorities to our clinic. They were referred for Neuropsychological functions and language assessment. These adopted children were between the ages of 2 years to 16 years. The sample was collected over a period of ten years. Demographic variables such as gender, occupation of parents, age of adoption of the child, sources of adoption, motor milestones, speech and language, and neuropsychological functions namely intelligence, memory, attention, concentration, other mental abilities and Specific Learning Disability (SLD) were assessed [10].

These children were assessed by Standardized Psychological Tests and HELP CHILD Learning Disability Assessment Tool.

\subsection{Neuropsychological and Language Functions Assessment}

Stanford-Binet Intelligence Scale - Stanford-Binet Intelligence Scale is used from age 2 to young adult. It contains wide variety of short, one to six item sub-tests measuring intellectual abilities. Besides intelligence it also measures mental abilities such as memory, comprehension, arithmetic reasoning, and perception of form, vocabulary \& Colour perception. Sub-tests are arranged in order of difficulty starting from year 2 . There are six sub-tests and an alternate at each level. Each sub-test has its own administration and scoring instructions [11].

Wechsler Memory Scale is the most commonly used Comprehensive Memory Scale consisting of seven sub tests Personal \& current information, Orientation, Mental control, Logical memory, Digits Span, Visual reproduction and associate learning. Memory Quotient (MQ) is derived as per the manual, which is comparable to Intelligence Quotient (IQ) [12].

Bhatia's Battery of Performance test of Intelligence is an intelligence test standardized in Indian population both literate and illiterate. It measures both performance IQ and full scale IQ [13].

Bender Visual Motor Gestalt test is a set of nine designs used to demonstrate the tendency of the perceptual system to organize visual stimuli. It measures visuomotor function [14].
Seguin -Goddard Form Board test is a visuo-spatial performance task which is used to assess the non-verbal intelligence of children [14].

Digit Span test is a sub test used in the Wechsler Intelligence scale comprised of two different tests, Digits forward (DF) and Digits backward (DB) [14].

HELP CHILD Learning Disability assessment tool is a comprehensive tool to assess writing, spelling, reading in English and second language i.e., Hindi / Tamil and Mathematics. It is standardized in regional population.

\subsection{Procedure}

A detailed case history was collected from the parents / care givers of these adopted children before the assessment. Each adopted child was assessed on the above Neuropsychological and Language tests in two to three sessions. Each session lasted for approximately ninety minutes. Assessment was done in English and regional language (Tamil).

\section{Results \& Discussion}

The data was analyzed using SPSS (Statistical Package for Social Sciences). The analysis showed $70 \%$ of adopted children have average and 30\% have above average IQ. 45\% of adopted children have average and 55\% have above average Performance IQ (PIQ). Memory, Attention \& Concentration were impaired in $20 \%$ of children. 14 children were assessed for Specific Learning Disability and all of them were found to have writing disorder, i.e., $100 \%$. $86 \%$ of children have reading disorder. Level of significance $\mathrm{Z}=$ 3.11, P = 0.01 (Mann Whitney U-test).

Comprehension was impaired in $20 \%$ of the adopted children. Impairment in Arithmetic reasoning 63\%, Vocabulary $26 \%$ and Perception of form $58 \%$ was seen in these children. Disturbance of the visuomotor function was seen in $18 \%$ of children. 18 fathers and 7 mothers were employed.

None of the children in the sample have biological siblings. 6 years 9 months was the mean age of adopted children. Mean age of adoption of children was 8 months 13 days (lowest age -7 days; highest age - 3 years).

Table 1. Neuropsychological functions vs Male-Female children.

\begin{tabular}{|c|c|c|c|c|c|c|}
\hline & \multicolumn{4}{|c|}{ Gender } & \multirow{2}{*}{\multicolumn{2}{|c|}{$\begin{array}{l}\text { Independent } \\
\text { Sample t-test }\end{array}$}} \\
\hline & \multicolumn{2}{|l|}{ Male } & \multicolumn{2}{|c|}{ Female } & & \\
\hline & Mean & SD & Mean & SD & t- Value & $\mathbf{P}$ \\
\hline IQ & 103.7 & 18.2 & 97.4 & 24.9 & .673 & .509 \\
\hline PQ & 116.2 & 16.5 & 103.9 & 28.0 & 1.183 & .254 \\
\hline Immediate Memory - DF & 5.0 & .8 & 4.3 & .8 & 1.665 & .117 \\
\hline Immediate Memory - DB & 3.9 & 1.1 & 3.3 & .6 & 1.000 & .350 \\
\hline Memory & 7.8 & 2.6 & 6.0 & 2.1 & 1.405 & .179 \\
\hline Arithmetic reasoning & 6.2 & 2.1 & 5.8 & 2.8 & .322 & .752 \\
\hline Perception form & 6.2 & 2.7 & 5.2 & 2.6 & .748 & .466 \\
\hline Vocabulary & 6.8 & 2.6 & 5.8 & 1.8 & .809 & .431 \\
\hline
\end{tabular}

Note: None of the parameters has any statistical significance with gender of adopted children 
Table 2. Neuropsychological functions vs Age of children.

\begin{tabular}{|c|c|c|c|c|c|c|c|c|}
\hline & \multicolumn{6}{|l|}{ Age } & \multirow{2}{*}{\multicolumn{2}{|c|}{ One way ANOVA }} \\
\hline & \multicolumn{2}{|c|}{$<5$ Years } & \multicolumn{2}{|c|}{5 -10 Years } & \multicolumn{2}{|c|}{$>10$ Years } & & \\
\hline & Mean & SD & Mean & SD & Mean & SD & F-Value & Sig. \\
\hline IQ & 100.6 & 29.4 & 104.4 & 16.2 & 94.8 & 14.5 & .298 & .746 \\
\hline$P Q$ & 113.8 & 16.1 & 113.9 & 26.3 & 102.8 & 19.2 & .374 & .694 \\
\hline Immediate Memory - DF & 4.0 & .0 & 4.9 & .9 & 5.3 & .6 & 3.231 & .070 \\
\hline Immediate Memory - DB & 3.0 & & 3.8 & 1.0 & 3.7 & 1.2 & .280 & .764 \\
\hline Memory & 5.2 & 1.3 & 7.7 & 1.8 & 12.0 & .0 & 14.075 & .000 \\
\hline Comprehension & 5.7 & .8 & 6.8 & 1.4 & 11.0 & 1.4 & 14.012 & .000 \\
\hline Arithmetic reasoning & 3.5 & .6 & 6.6 & 1.7 & 9.0 & .0 & 11.811 & .001 \\
\hline Perception form & 3.4 & .5 & 5.8 & 2.0 & 10.0 & .0 & 16.651 & .000 \\
\hline Vocabulary & 5.0 & .0 & 6.5 & 2.2 & 10.5 & 2.1 & 6.439 & .010 \\
\hline
\end{tabular}

Table 3. Neuropsychological functions vs Age of adoption.

\begin{tabular}{|c|c|c|c|c|c|c|c|c|c|c|}
\hline & \multicolumn{8}{|c|}{ Age of adoption (Months) } & \multirow{2}{*}{\multicolumn{2}{|c|}{ One way ANOVA }} \\
\hline & \multicolumn{2}{|c|}{1 month or less } & \multicolumn{2}{|c|}{$2-5$ months } & \multicolumn{2}{|c|}{$6-10$ months } & \multicolumn{2}{|c|}{$>10$ Months } & & \\
\hline & Mean & SD & Mean & SD & Mean & SD & Mean & SD & F-Value & Sig. \\
\hline IQ & 82.8 & 34.4 & 105.3 & 10.6 & 97.7 & 16.2 & 110.2 & 18.0 & 1.763 & .192 \\
\hline$P Q$ & 115.5 & 9.2 & 108.1 & 16.9 & 109.0 & 26.2 & 115.0 & 30.7 & .120 & .947 \\
\hline Immediate Memory - DF & 5.0 & 1.0 & 4.8 & .4 & 5.7 & .6 & 4.0 & .7 & 4.380 & .024 \\
\hline Immediate Memory - DB & 4.0 & 1.4 & 3.2 & .4 & 4.3 & 1.2 & . & & 1.686 & .253 \\
\hline Memory & 9.3 & 3.1 & 6.4 & 2.2 & 10.0 & 2.0 & 5.8 & 1.1 & 3.876 & .033 \\
\hline Comprehension & 8.0 & 4.0 & 6.3 & 1.4 & 8.7 & 1.2 & 6.0 & .0 & 1.993 & .161 \\
\hline Arithmetic reasoning & 8.5 & .7 & 5.2 & 2.2 & 8.0 & 1.0 & 4.8 & 1.5 & 3.749 & .045 \\
\hline Perception form & 6.7 & 3.5 & 5.9 & 2.4 & 8.7 & 1.5 & 3.6 & .9 & 3.539 & .043 \\
\hline Vocabulary & 6.3 & 3.1 & 6.3 & 2.1 & 9.7 & 2.1 & 5.0 & .0 & 3.701 & .040 \\
\hline
\end{tabular}

The above results showed significant difference in overall Memory function, Arithmetic Reasoning, Perception of form and Vocabulary among children with different age of adoption. Children who were adopted between 6 to 10 months of age have no disturbance in Memory, perception of form, and vocabulary. Children who were adopted in less than one month had no disturbance in Arithmetic reasoning. Neuropsychological functions were found to be impaired in children who were adopted after 10 months of age.

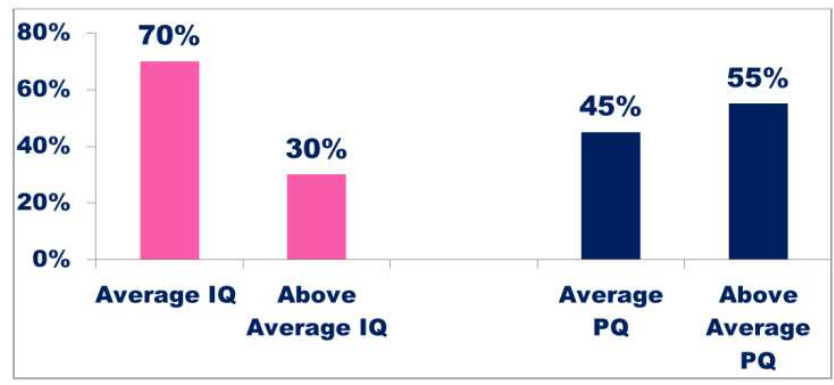

Figure 1. Comparison of IQ vs $P Q$ in adopted children.

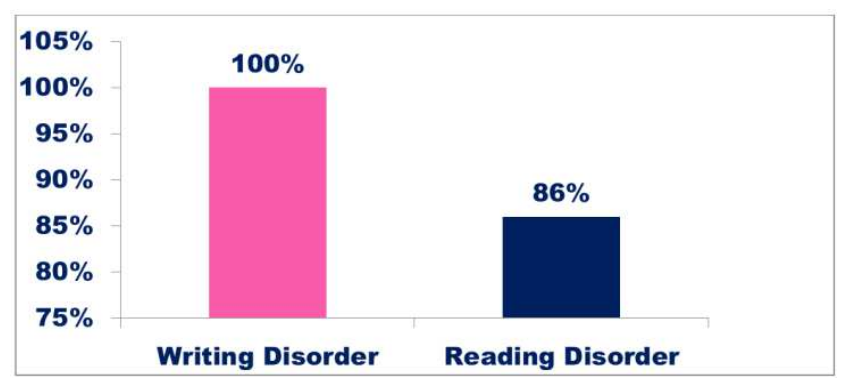

Figure 2. Presence of Specific Learning Disorder in adopted children.
The above figure showed all the children have writing disorder and $86 \%$ of children have reading disorder.

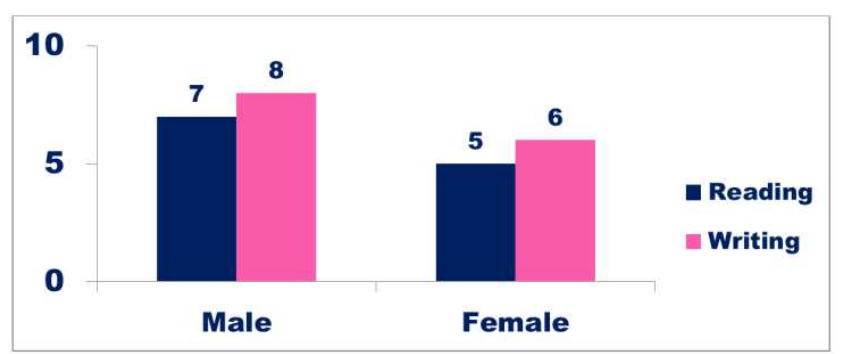

Figure 3. Presence of Specific Learning Disorder in adopted children vs Gender difference.

The above results showed writing disorder seemed to be more in both male and female children.

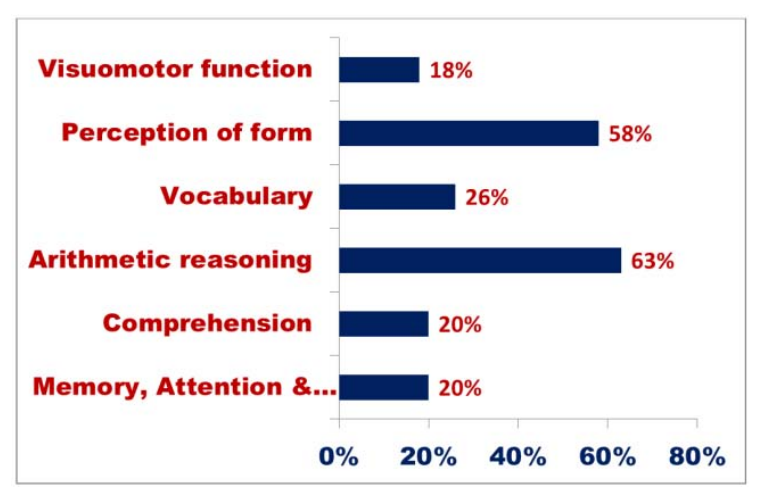

Figure 4. Impairment of Neuropsychological functions in adopted children.

Above figure shows that more than $50 \%$ of children have impairment in perception of form and arithmetic reasoning. 

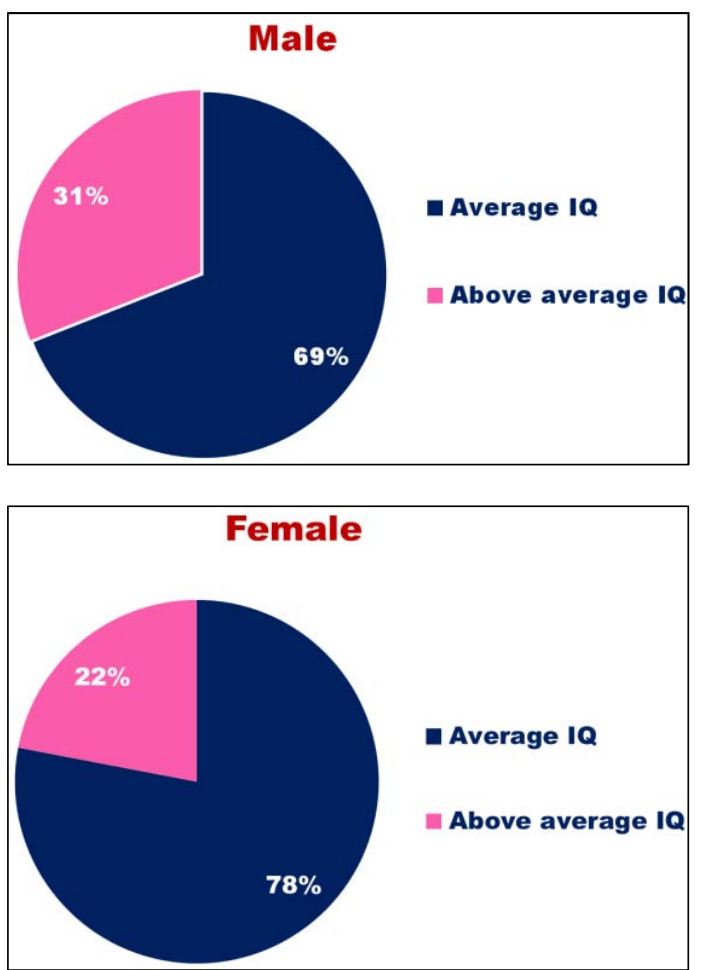

Figure 5. IQ vs Gender difference.

$31 \%$ of male children have average IQ and $69 \%$ have above average IQ. $22 \%$ of female children have average IQ and $78 \%$ above average IQ.
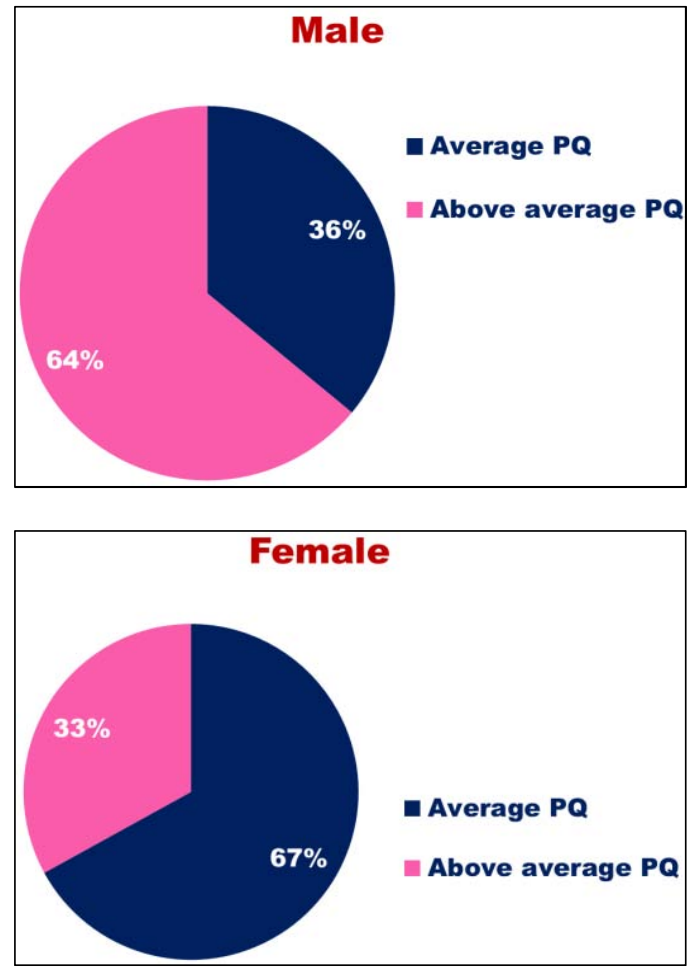

Figure 6. $P Q$ vs Gender difference.

$36 \%$ of male children have average PQ and $64 \%$ have above average PQ. 33\% of female children have average PQ and $67 \%$ above average PQ.

\section{Conclusions}

Neuropsychological profile showed majority of adopted children have average IQ and above average PQ. $1 / 5^{\text {th }}$ of the children have impairment in memory, attention and concentration. Almost all the adopted children have Specific Learning Disorder. $3 / 5^{\text {th }}$ of the children have impairment in arithmetic reasoning and perception of form. Adopted children need to be screened not only for neuropsychological functions but also for language functions - writing, reading and arithmetic. This assessment helps in planning appropriate management and remedial intervention for the adopted children to overcome the psychological impairment and learning disorders. Early identification and appropriate remedial intervention will be helpful for better academic performance.

\section{Acknowledgements}

We thank all the children and their parents who participated in this study. We also thank Mrs. Amutha for her assistance in the preparation of this manuscript. There is no funding to report for this research work. The authors report no conflicts of interest.

\section{References}

[1] Radha, S. A., \& Oommen, Anna (2006). Psychopathology and adjustment in adopted children: A Clinic based study. Indian Journal of Clinical Psychology, 33, 72-77.

[2] Stephen Krauss (1976). Encyclopaedic Handbook of Medical Psychology. Butterworth \& Co. Publishers Ltd. London, 5-6.

[3] William M. Klykylo (2005). Clinical Child Psychiatry $\left(2^{\text {nd }}\right.$ Ed.) John Wiley \& Sons Ltd. England, 525-527.

[4] Hersov, L. (1990). The Seventh Jack Tizard Memorial Lecture. Aspects of Adoption. Journal of Child Psychology \& Psychiatry, 31, 493-510.

[5] Kirthi Rao et. al (2006). Psychological Adjustment in adopted children. Indian Journal of Clinical Psychology, 33, 87-92.

[6] Schechter, M. D., Carlson, P. V., Simmons, J. Q., \& Work, H. H. (1964). Emotional problems in the adoptees. Archives of General Psychiatry, 10,109-118.

[7] Mech, E. V. (1973). Adoption: A policy perspective. Cited in Smith, D. W. and Brodzinsky, D. M. (1993). Stress and coping in adoption. A developmental perspective. Journal of Child Psychology, 29, 91-99.

[8] Rogeness, G. A., hoppe, S. K., Macedo. C. A., Fischer, C. \& Harris, W. R. (1988). Psychopathology in hospitalized adopted children. Journal of American Academy of Child and Adolescent Psychiatry, 27, 628-631.

[9] Biemen, V. H. J. M., \& Verhulst, F. C. (1995). Self reported and parent reported problems in adolescent international adoptees. Journal of Child Psychology and Psychiatry, 36, 1411-1428. 
[10] Diagnostic and Statistical Manual for Mental disorders (2013). American Psychiatric Association, (5 ${ }^{\text {th }}$ ed.) Washington, DC: Author.

[11] Terman, L. M. \& Merrill, M. A. (1973). Stanford-Binet Intelligence Scale, Manual for the third revision, Form, L-M. Boston: Houghton Mifflin.

[12] Wechsler, D (1945) Wechsler Memory Scale, A Standardized Memory Scale for clinical use. Journal of Psychology, 19,8795 .

[13] Bhatia, C. M. (1955). Bhatia's Performance Test of Intelligence, Oxford University Press.
[14] Lezak, M. D. (1983). Neuropsychological Assessment $\left(2^{\text {nd }}\right.$ Ed.) New York: Oxford University Press.

[15] Kohli et. al (2007). Deficit and Clinical profile on the children with Specific Learning Disability. Indian Journal of Clinical Psychology, 34,173-181.

[16] S. Venkatesan (2016). A concept analysis of Learning Disability based on research articles published in India. Indian Journal of Clinical Psychology, 43,97-107. 